\title{
O MUNDO É UM MOINHO: SACRIFÍCIO E COTIDIANO EM MÁRIO DE ANDRADE
}

\author{
André Botelho \\ Universidade Estadual de Campinas (Unicamp), Campinas, SP; \\ Universidade Federal do Rio de Janeiro (UFRJ) Rio de Janeiro, RJ. Brasil. \\ E-mail:<andrebotelho@digirotas.com.br > \\ Maurício Hoelz \\ Universidade Federal do Rio de Janeiro (UFRJ. \\ Rio de Janeiro, RJ.Brasil.E-mail<mauriciohoelz@gmail.com>
}

http://dx.doi.org/10.1590/ 0102-6445251-284/97

A atuação prolífica e diversa de Mário de Andrade na imprensa constitui um dos vezos mais recursivos em que transcorre a sua vida-obra. São conhecidas, porém, suas angústias em relação às atividades cotidianas que o absorviam, sentidas ambiguamente como, de um lado, estratégicas para reconciliar a arte e a sociedade à cultura popular brasileira, e, de outro, como tempo roubado à formulação de uma obra mais integrada e teoricamente sistemática. Não há razões para minimizar a relevância pecuniária envolvida na atividade da imprensa - ainda mais em um contexto de mercado editorial tão precário como o do modernismo brasileiro -, tampouco a autoridade decorrente de sua presença contínua nas páginas dos jornais, nos termos da formação de uma rotina intelectual modernista. Ainda assim, sustentamos que suas relações ambíguas com a imprensa não se reduzem inteiramente à matriz dos interesses. Antes, argumentamos que é a ideia de sacrifício - indissociável, a nosso ver, da questão do cumprimento do destino intelectual - que permite articular as diferentes dimensões entre trajetória e obra em Mário de Andrade. E, sociologicamente, essa ideia faz sentido justa- 
mente porque não há, no Brasil dos modernistas, algo estruturado em termos próximos aos de um campo intelectual autônomo, com posições diferenciadas e regidas exclusivamente por um habitus próprio em seu interior e nas relações inclusivas mantidas por seus membros com a sociedade (Bastos e Botelho, 2010). Assim, pode-se dizer que a missão de que se investe Mário como que sacraliza sua entrega à causa modernista, não apenas justificando-a subjetiva e objetivamente, mas tornando relativa a própria dualidade entre permanência e efemeridade de sua obra intelectual. Para discutir a questão, concentraremos nosso comentário em artigos de crítica musical do líder modernista, uma das modalidades mais constantes de sua atuação na imprensa.

\section{Destino intelectual e cotidiano}

Mário de Andrade angustiava-se constantemente por se ver assoberbado de atividades cotidianas, seja na imprensa, no

252 ensino de música, nas atividades de gestão pública na área cultural ou para manter em dia sua vasta correspondência. Experimentava-as ambiguamente: eram necessárias à causa maior modernista de tornar o Brasil mais familiar aos brasileiros, mas acabavam por dissipar sua própria energia criativa e intelectual, que poderia ser canalizada para a realização de um projeto intelectual mais integrado e teoricamente sistemático. Em um de seus frequentes exercícios de autoanálise através da epistolografia, Mário revela a Henriqueta Lisboa que, de todos os seus "vícios", o que mais lhe consumia no cotidiano era o trabalho. Confessa que, para tê-lo sob controle, chegou mesmo a manter uma espécie de diário de vivência, no qual tinha o curioso hábito de atribuir a si mesmo uma "nota de aprovação vital" (Andrade, 2010, p. 232).

Como tudo o mais em Mário de Andrade, a angústia causada por sua dedicação à imprensa, vista como atividade intelectual contingente e efêmera, em contraste com o ideal de uma obra acabada e duradoura, é sempre também 
ambígua, bem como os efeitos práticos ou pretendidos de sua militância na imprensa, por assim dizer. Ainda na correspondência com Henriqueta, diz:

[...] o que eu valho, talvez fique mais nas cartas e nas formas subterrâneas de vida, as conversas, a presença do amigo, a força de uma inteligência auxiliar, coisas assim. [...] Jamais pretendi ficar. Sou excessivamente sensual, por demais gostador do minuto que passa, pra economizar minhas forças (que reconheço, sem vaidade, muito grandes) e realizar a obra de arte com valor permanente (Andrade, 2010, p. 165; grifo no original).

No mesmo sentido, é emblemática a ideia de "procura" expressa na advertência que abre seu livro de poesia Losango cáqui, de 1924:

Porém peço que este livro seja tomado como pergunta, não como solução que eu acredite sequer momentânea. A existência admirável que levo consagrei-a toda a procurar. Deus queira que não ache nunca... Porque seria então o descanso em vida, parar mais detestável que a morte. Minhas obras todas na significação verdadeira delas eu as mostro nem mesmo como soluções possíveis e transitórias. São procuras. Consagram e perpetuam esta inquietação gostosa de procurar. Eis o que é, o que imagino que será toda a minha obra: uma curiosidade em via de satisfação (Andrade, s.d., p. 79).

Para Mário, afinal, a arte, assim como a religião ou a eletricidade (o exemplo é dele mesmo), seria antes uma realização cotidiana:

Jamais sentei nesta secretária tumultuosa pra escrever uma "obra-prima". Mas aqui tenho sentado cotidianamente pra viver. [...] a arte é como fumar, comer, corrigir suas 
provas de colégio, saudar o vizinho agradável e não saudar o vizinho desagradável: um exercício cotidiano da vida (Andrade, 2010, p. 168).

Contudo, apesar dessas e outras afirmações similares - das quais não se pode negligenciar o componente retórico -, subsistia no horizonte de expectativas do autor o ideal normativo de obra acabada a operar como um ponto de fuga na automodelagem de seu self, ora em registro negativo, impelindo-o a recorrentes autojustificações, ora em registro positivo, como em seus estudos para o curso de filosofia da estética ministrado na Universidade do Distrito Federal, no Rio de Janeiro.

O tema do cumprimento do destino intelectual é recursivo na obra de Mário de Andrade como um todo, e se faz presente de modo particularmente marcante em suas últimas poesias, mas também ao longo de sua vasta correspondência - para dar dois exemplos bastante diferentes: na que mante254 ve com Manuel Bandeira (com quem cultivava uma relação mais igualitária) e na estabelecida com Carlos Drummond de Andrade, mais jovem do que Mário (com quem desenvolvia uma relação mais doutrinária). O tema aparece, por exemplo, nesta passagem sobre Ronald de Carvalho em carta trocada com Bandeira, em 1924, no contexto do conhecido episódio de ruptura entre segmentos dos modernistas paulistas e cariocas, deflagrado pela publicação do artigo "O lado oposto e outros lados”, de Sérgio Buarque de Holanda; relata Mário:

[...] o Ronald pela extraordinaríssima inteligência que tem deve dar mais do que tem dado e dá na sua prosa para jornal, revistas, conferências [...] pode fazer na prosa qualquer coisa de mais duradouro que vulgarizações literárias. Deixe isso para nós, eu, que não tenho a mesma harmonia e concorrência igual de faculdades intelectivas. Eu não passo dum vulgarizador. Sei do meu destino e o cumpro com consciência (Andrade, 2000, p. 136). 
Concordando com Mário de Andrade que o "escrever para jornais e conferências prejudica o artista”, Manuel Bandeira salienta ironicamente que, no caso de Ronald de Carvalho, não lastimava "muito que o artista ficasse um pouco sacrificado com isto - para bem da Pátria e felicidade geral da nação" (Andrade, 2000, p. 139).

Como identidade e subjetividade são relações, muitos são os "Mários" da epistolografia, porque muitos foram os seus interlocutores. Criação, circulação e confrontação de ideias modernistas, porém, emergem como centro desse universo reflexivo potencialmente plural e sem fim. E nessa interlocução múltipla sobre o modernismo, Mário de Andrade acaba por exercer uma "pedagogia epistolar" toda própria, especialmente aberta à juventude, e que assume o sentido de um projeto, procurando tocar cada um e a todos (Moraes, 2007). É o caso da correspondência com Drummond, mantida por mais de vinte anos, de 1924 até às vésperas da morte de Mário, em 1945, na qual flagramos o cotidiano de dois grandes artistas e intelectuais, e também nos emocionamos ao perceber a sua correspondência como uma espécie de metrônomo que marca o tempo não apenas objetivo, mas o próprio andamento de uma amizade que se mostrou crucial na trajetória dos dois autores e na formação do próprio modernismo. E, para além do conteúdo que atravessa e abre a correspondência - revelador do caráter da aprendizagem estética, moral e intelectual em jogo -, existe ainda a dimensão da vivência ou da experiência do outro, cuja presença sempre afeta sensivelmente os dois (ou mais) lados da correspondência (Santiago, 2002; Moraes, 2007; Araújo, 2014; Botelho, 2015). Vejamos um longo trecho no qual a tópica do sacrifício é central:

Carlos, devote-se ao Brasil, junto comigo. Apesar de todo o ceticismo, apesar de todo o pessimismo e apesar de todo o século 19, seja ingênuo, seja bobo, mas acredite que um sacrifício é lindo. O natural da mocidade é crer e muitos 
moços não creem. Que horror! Veja os moços modernos da Alemanha, da Inglaterra, da França, dos Estados Unidos, de toda a parte: eles creem, Carlos, e talvez sem que o façam conscientemente, se sacrificam. Nós temos que dar ao Brasil o que ele não tem e que por isso até agora não viveu, nós temos que dar uma alma ao Brasil e para isso todo sacrifício é grandioso, é sublime. E nos dá felicidade. Eu me sacrifiquei inteiramente e quando eu penso em mim nas horas de consciência, eu mal posso respirar, quase gemo na pletora da minha felicidade. Toda a minha obra é transitória e caduca, eu sei. E eu quero que ela seja transitória. Com a inteligência não pequena que Deus me deu e com os meus estudos, tenho a certeza de que eu poderia fazer uma obra mais ou menos duradoura. Mas que me importam a eternidade entre os homens da Terra e a celebridade? Mando-as à merda. Eu não amo o Brasil espiritualmente mais que a França ou a Cochinchina. Mas é no Brasil que me acontece viver e agora só no Brasil eu penso e por ele tudo sacrifiquei. A língua que escrevo, as ilusões que prezo, os modernismos que faço são pro Brasil. E isso nem sei se tem mérito porque me dá felicidade, que é a minha razão de ser da vida. Foi preciso coragem, confesso, porque as vaidades são muitas. Mas a gente tem a propriedade de substituir uma vaidade por outra. Foi o que fiz. A minha vaidade hoje é de ser transitório. Estraçalho a minha obra. Escrevo língua imbecil, penso ingênuo, só pra chamar a atenção dos mais fortes do que eu pra este monstro mole e indeciso ainda que é o Brasil. Os gênios nacionais não são de geração espontânea. Eles nascem porque um amontoado de sacrifícios humanos anteriores lhes preparou a altitude necessária de onde podem descortinar e revelar uma nação. Que me importa que a minha obra não fique? É uma vaidade idiota pensar em ficar, principalmente quando não se sente dentro do corpo aquela fatalidade inelutável que move a mão dos gênios. O importante não é ficar, é viver. Eu vivo (Andrade, 2015, pp. 21-22). 
Assim, vemos como a questão do cumprimento do destino intelectual não se dissocia da tópica do sacrifício com que Mário de Andrade busca qualificar sua missão modernista. Sacrifício é uma categoria que faz sentido justamente porque não há, no Brasil dos modernistas, algo estruturado em termos próximos aos de um campo intelectual autônomo. Por isso, as tentativas de desmistificação das ideias do autor por meio da exposição da matriz de seus interesses não esgotam os sentidos sociológicos das, digamos, veleidades que os intelectuais são capazes de, ou levados a, nutrir sobre si próprios e o seu papel social, dada a tenacidade com que a própria sociedade brasileira, tão profundamente marcada por um processo de formação autocrático, tem instigado a participação dessas suas minorias problemáticas.

Evidentemente, não se pode desprezar a relevância pecuniária desse trabalho fragmentário de crítico de arte e música na imprensa, sobretudo num contexto de mercado editorial tão incipiente e mesmo acanhado como o do modernismo brasileiro, e para um professor de música que dependia de seu próprio trabalho intelectual, como Mário de Andrade. Bastaria, a esse propósito, consultar um dos anexos de $A$ lição do amigo (Andrade, 2015), no qual Carlos Drummond de Andrade apresenta extensa relação de trechos sobre o tema da dificuldade financeira nas cartas de Mário. A colaboração de Mário na imprensa constituiu mesmo uma rotina, pontuando seu dia a dia, e foi fundamental para modelar a sua feição como intelectual público, em geral, e como crítico, em particular; esta última atividade forjada em jornais como Jornal do Comércio e A Gazeta - nos quais estreou como crítico literário em 1921 -, Correio Paulistano, A Manhã, Diário Nacional, Diário de São Paulo e O Estado de S. Paulo, Diário de Noticias, Correio da Manhã, entre outros (Sachs, 1993). Do mesmo modo, é preciso levar em conta a autoridade conferida por sua colaboração contínua nos jornais de grande circulação e nas revistas modernistas como componente que concorreu 
tanto para a formação de uma rotina intelectual modernista, quanto para a legitimidade da liderança exercida por Mário no modernismo como movimento cultural. As duas dimensões se inter-relacionam intimamente, como observou Sônia Sachs (1993, p. ix).

Preso a necessidades financeiras, Mário viu-se desgastado pela tarefa constante e sentiu o peso dessa obrigação de escrever para jornal. Mas a verdade é que aquele que viveu da fé na arte e nos homens - como ele sempre repetia encontrou na crônica jornalística um forte instrumento de ação, já que a frequência e a ligeireza dos artigos, além de suscitar a discussão, permitiam-lhe orientar de perto os escritores novos, em uma espécie de missão de vida.

Se "interesse" e "autoridade" se imbricam, não há motivo para reduzir sociologicamente a participação de Mário 258 de Andrade na imprensa a um ou a outro desses princípios de coordenação social isoladamente. Como formula Max Weber (apud Bendix, 1986), na vida social sobrepõem-se empiricamente três princípios de orientação das condutas, distinguíveis somente analiticamente pelos construtos conceituais que denomina "tipos ideais": o interesse, a autoridade e a solidariedade. Isso parece suficiente para problematizar o privilégio, necessário ou exclusivo, atribuído por qualquer interpretação sociológica à matriz dos interesses. Qualquer ênfase sobre uma dimensão ou outra, neste caso, será sempre um recurso parcial, porque analítico.

Portanto, uma estratégia mais produtiva para tratar a participação de Mário de Andrade na imprensa, mesmo considerando as relações entre posição social e estruturas de poder, implicaria não ignorar outras dimensões sociais imbricadas, como já formulado a respeito da geração modernista em geral e de Mário de Andrade em particular (Miceli, 2001, 2009; Bomeny, 2012; Jardim, 2015). Tampouco gosta- 
ríamos de corroborar, por isso, a ideia de um ethos da desvinculação social historicamente cultivado pelos intelectuais brasileiros a respeito de si próprios. No entanto, não nos parece suficiente combater essa autorrepresentação dos intelectuais simplesmente expondo a matriz dos interesses que lhes seria subjacente, abordando para tanto suas relações com as classes dirigentes como estratégicas para a explicação das posições por eles assumidas no "mercado de postos" em expansão na sociedade brasileira entre 1920 e 1945, tanto no setor privado como no público, em especial nas estruturas de poder do Estado (Miceli, 2001). A ideia de cooptação, que adquire sentido nos marcos de uma sociologia classista, pode até ser explicativa do intercâmbio entre as forças sociais que se organizam nas estruturas de poder e os intelectuais, quando estes são tomados por seus laços familiares, pessoais ou sociais. Mas o mesmo não é válido quando se tem em vista os seus escritos (Bastos e Botelho, 2010), que, embora não sejam autônomos, extrapolam uma estrita circunscrição social.

Ainda que não se trate de desenvolver extensivamente a tópica do sacrifício em Mário de Andrade, que vem recebendo atualmente cada vez mais atenção, ademais como forma de autocompreensão da "missão" ou "papel social" de que, como os intelectuais de sua época, o líder modernista se sentia investido (Fragelli, 2012, 2013; Araújo, 2014), podemos, porém, fazer duas observações gerais em prol de suas necessárias ampliação e qualificação. A primeira é que, a exemplo das "classificações primitivas" estudadas em um texto clássico por Durkheim e Mauss - as quais articulam simultaneamente o indivíduo e a sociedade, o corpo e a alma, os vivos e os mortos, o passado e o presente, o macrocosmo e o microcosmo social -, a noção de sacrifício é o que articula as diferentes dimensões entre trajetória e obra em Mário de Andrade, transcendendo o estatuto de "tema" para o de "forma". A segunda é que o estudo mais profundo das raízes 
dessa noção no encontro entre cultura popular e catolicismo brasileiro, que Mário de Andrade também soube tornar tão particular, encontra-se em aberto - embora o tema do catolicismo venha recebendo recentemente aportes importantes (Monteiro, 2012). Gostaríamos apenas de sugerir que, para a feição bastante particular assumida pelo catolicismo de Mário de Andrade, terá concorrido, antes de tudo, sua empatia mais ampla com a cultura popular, sendo esta mesma, aliás, uma matriz importante para a ideia de sacrifício e seu estudo, como pretendemos desenvolver noutras oportunidades. Bastando lembrar, neste momento, da centralidade dessa tópica nos bailados e danças dramáticas do boi pesquisados ao longo da vida por Mário (Cavalcanti, 2004).

A nosso ver, justamente a dificuldade manifesta pelas diferentes correntes intelectuais católicas contemporâneas ao modernismo, em geral então muito elitistas, em lidar com a cultura popular foi o calcanhar de Aquiles do tra260 dicionalismo católico dos anos de 1920-40, seja ele o mais ortodoxo, como em boa parte da trajetória de Alceu Amoroso Lima, ou o extramuros, e mais heterodoxo, como em seu cunhado, Octavio de Faria, por exemplo. De um e outro lado, o catolicismo popular brasileiro é visto como misturado a diversas práticas tidas como supersticiosas por parte da hierarquia da igreja e de seus intelectuais e, portanto, distantes das práticas e da doutrina oficial católica. Não é à toa que Dom Sebastião Leme, ator preponderante naquele contexto, afirma ser a "ignorância religiosa" o grande problema do Brasil. Não será à toa também que o lugar da cultura popular na formação social do país, e em sua intepretação, seja aspecto central no debate de Alceu Amoroso Lima e Mário de Andrade, como se pode ler, por exemplo, na correspondência mantida entre eles. É o caso da carta datada de 6 de março de 1931, onde Mário se defende da acusação de Alceu de estar "estragado, ou coisa assim, pela 'mania etnográfica”, retrucando que a etnografia 
[...] não é mania em mim, mas é uma salvação de mim (porque me impede ou me livra de tomar socialmente posição em assuntos a que sou naturalmente infenso, atitude política, atitude religiosa social...), e também um jeito de saber [...] é um dos meus muitos jeitos de procurar o Brasil (Andrade, 1968, p. 27).

O motivo da peleja não foi outro senão a observação de Mário de que não havia encontrado no vasto material popular por ele coligido ao longo de anos elementos que corroborassem a tese do líder católico sobre as supostas raízes católicas do Brasil. Acrescenta Mário:

Você não me viu afirmar que o brasileiro é acatólico, por causa duns cinquenta fenômenos sociais e não individuais, que são apenas fenômenos de acatolicidade. Mas de qualquer forma você não poderá em consciência negar a utilidade da documentação ajuntada. E que eu poderia continuar, se em vez de crítica e movimentação de noções, tivesse que fazer um tratado sobre (Andrade, 1968, pp. 27-28; grifos no original).

Catolicismo e cultura popular são assim chaves para a compreensão da própria noção de sacrífico como forma em Mário de Andrade. Questões estas, porém, para serem tratadas noutra oportunidade.

Lembrando por ora apenas outro texto de Marcel Mauss, se sacrifício é "um ato religioso que, mediante a consagração de uma vítima, modifica o estado da pessoa moral que o efetua ou de certos objetos pelos quais ela se interessa" (Mauss e Hubert, 2005, p. 19), podemos dizer que a atuação de Mário de Andrade na imprensa opera essa modificação no cumprimento de seu destino intelectual. Porque o sacrifício, noutras palavras, forja um espaço simbólico relacional em que as duas partes envolvidas saem modificadas - tanto o sujeito quanto o objeto do rito. Na medida em que consideramos também a 
dimensão propriamente narrativa de seus artigos, o trabalho cotidiano e fragmentário do modernista na imprensa - seu sacrifício - figura um espaço existencial, situado entre trajetória e obra, a partir do qual forja e aperfeiçoa o gênero crônica, cuja cotidianidade, ademais, mostrar-se-ia tão fértil para o seu programa estético de recriação da linguagem falada em escrita. Ao contrário do que vinha sendo explorado, em grande medida, pelas gerações anteriores e segmentos contemporâneos - como atesta a pergunta sobre o significado do jornalismo para a literatura na enquete "O momento literário", promovida por João do Rio no início do século XX -, Mário de Andrade busca aproximar literatura e imprensa, antes tornando a literatura um espaço do cotidiano do que procurando enobrecer a imprensa, tornando-a literária. Mas como o sacrifício não representa, e sim repete o gesto de transformação, a ambiguidade entre permanência e efemeridade não desaparece simplesmente, persiste, tragicamente, como destino. Desse modo, 262 embora possamos concordar com a ideia de persistência de uma relativa antinomia entre o "valor político" e "valor estético" no pensamento de Mário de Andrade, como se o "engajamento" por ele defendido não deixasse de acarretar o "sacrifício da qualidade estética da obra de arte" (Fragelli, 2013, p. 88 ), interessa-nos explorar mais as suas ambiguidades, a ponto de poder surpreender inclusive o cumprimento de seu destino intelectual por vias que nem sempre estiveram claras para ele mesmo. Como o sacrifício, afinal, como lembramos antes, transforma não apenas o sujeito, mas o objeto do rito, a própria dualidade entre permanência e efemeridade da obra de Mário de Andrade acaba por ser relativizada.

A correspondência de Mário com Henriqueta Lisboa, anteriormente referida, é rica também a propósito da questão do cumprimento do destino intelectual. Em outra carta para a poetisa mineira, datada de 12 de setembro de 1943, Mário a informa que, no ano anterior, decidira deixar de lado o diário que vinha tentando manter para controle 
daquele que seria o pior dos seus "vícios", o trabalho, e do qual já dera notícia a amiga em carta de 7 de dezembro de 1942. Observa Mário que, folheando o diário abandonado, surpreendeu-se em constatar o quanto o que nele havia anotado se referia a pedidos de amigos e demandas criadas por terceiros, antes que aos seus próprios projetos mais pessoais. Essa ambiguidade envolvida no cumprimento do seu destino intelectual, como sempre, não passa despercebida a Mário, o que, como pondera a amiga, fazendo a lista do que já havia escrito a pedido de outros apenas nos últimos dois meses, "não deixa de ser bastante melancólico, embora seja humano profundamente e glorioso mais que tudo, e é mesmo a resultante fatal do destino que me dei" (Andrade, 2010, p. 264).

Na mesma carta, autocrítico, confessa à amiga que, relendo seus escritos de jornal, também por "necessidades provocadas por outros", o que mais lhe incomodava eram o que chama de suas "descaídas".

Meu Deus! como meu espírito foi lento a se desenvolver! Chega a ser absurdo! Num raríssimo artigo o pensamento até vai indo bem direitinho, mas de repente encontro cada descaída, cada burrice, cada tolice que me sinto enrubescer lendo essas coisas. Na verdade o meu espírito só principia demonstrando algum (apenas "algum”) equilíbrio de maturidade ali por 1926, 27. E só já não tem mais propriamente razão para se envergonhar de si, e das burradas que faz (burradas, mas já harmoniosas) depois de 1932. E eu tinha então 39 anos! Não é assombroso? Não pense que estou sendo pessimista não, nem humildade nem nada. É a verdade verdadeira (Andrade, 2010, p. 265).

Ponderado, Mário observa que, talvez, até houvesse em seus artigos de jornal de mocidade "coisas argutas" - "coisas que sustento, coisas que até imagino bem pensadas e bem desenvolvidas" -, mas o que lhe assombraria neles seriam as 
suas "descaídas". E ressalva que não pôde se beneficiar em sua juventude da interlocução que passou a ter e mesmo a proporcionar aos jovens, com troca de textos inéditos e “opiniões e censuras" sobre eles (a exemplo das que vinha mantendo com Manuel Bandeira e Carlos Drummond de Andrade, como destaca). Se esse diálogo intelectual houvesse ocorrido, avalia, suas "descaídas" não seriam tantas, ou talvez elas não o aborrecessem tanto.

Na sequência de sua exposição a Henriqueta Lisboa, Mário apresenta ainda mais um elemento, a nosso ver, muito importante para a qualificação do tema do cumprimento do seu destino intelectual. Sugere que, como o modernismo despiu de artifícios linguísticos e estéticos a prosa e a poesia, ele mesmo ficou sem o relativo benefício que estes ofereceriam, já que, como "dantes o escritor, tivesse a idade que tivesse era obrigatoriamente 'bem-pensante', o coturno e a sobrecasaca da frase ao menos dava uma aparência à burrice" 264 (Andrade, 2010, p. 266). Percebe-se, aqui, como a própria transfiguração na linguagem literária - e também na ensaística -, que a aproximação modernista ao cotidiano implicou, é ela mesma objeto da reflexividade sempre ambígua de Mário de Andrade, ainda que, justamente, isso reforce nossa hipótese de que a linguagem desataviada do modernismo parece também ter sido experimentada, como estamos argumentando, como um efeito do rito sacrificial da sua entrega às demandas contingentes e fragmentadas da imprensa. Como diz à Henriqueta Lisboa: "Mas com o modernismo, jogamos fora coturno e sobrecasaca da frase, a burrice, a tolice, ficou nua. E eu nunca tive ninguém que me evitasse as descaídas, minha obra de revista e de jornal é péssima” (p. 266).

\section{Um pensamento como percurso}

Aturdido pelas "descaídas" do seu pensamento, Mário de Andrade chegou a dizer que desautorizava tudo quanto fosse página escrita por ele em jornal antes dos quarenta anos; 
porém, ao mesmo tempo, acreditava que "o gênero 'de circunstância' pode da mesma forma que qualquer outro provocar coisas eterníssimas e geniais" (Andrade, 2010, pp. 266, 291). Talvez, por essa razão, Mário tenha se dedicado a colecionar com zelo boa parcela de sua produção jornalística, desse modo como que a retirando da ordem do efêmero e acalentando a possibilidade de lhes dar existência mais longeva, o que, aliás, ocorreu com os artigos recolhidos em Música, doce música. Os textos, recortados, eram organizados em pastas ou em dois álbuns grandes, encadernados em pano couro preto; adotava geralmente uma classificação por gênero. Dois álbuns cobrem o período de 1918-35, reunindo o segundo deles, nomeado Recortes $I V$, a maior parte das crônicas que publicou no Diário Nacional (Lopez, 1976, p. 21). Em um envelope de papelão, transformado em pasta - sobre o qual escreveu a lápis azul: "Artigos/ meus/ sobre Música/ (publicáveis em livro?)”-, Mário reuniu vários textos de crítica musical, datilografados ou recortados, que escreveu entre 1921 e 1932. Transparece aí também a ambiguidade de uma espécie de desejo sequestrado de permanência na transitoriedade.

Os álbuns denominados "Recortes" guardam textos de jornais e revistas, nacionais e estrangeiras, sobre variados assuntos do interesse de um sempre múltiplo Mário de Andrade. O escopo de áreas compreendido pela coleção de recortes é bastante amplo: produção, crítica, noticiário, teoria e (pouca) iconografia sobre música; produção, crítica e noticiário sobre as literaturas francesa, portuguesa, espanhola, hispano-americana, argentina, alemã, brasileira; artes plásticas; estética; religião; folclore; medicina; cinema; fotografia; sociologia, etnologia e antropologia; geografia; língua portuguesa; entre outras. No que diz respeito particularmente à música, Mário recebia de amigos na Europa livros e textos de periódicos que lhe serviriam para estudo, notícias e críticas de jornais sobre artistas brasileiros em 
tournée no exterior - as de Villa Lobos, por exemplo, seriam reunidas em "dossiê" próprio - ou sobre a repercussão da música nacional em geral. Além disso, os recortes sobre crítica musical abrangem escritos dos principais críticos musicais da época, com a maioria dos quais o epistolomaníaco Mário mantinha correspondência - Renato Almeida, Oscar Lorenzo Fernandez, João Caldeira Filho, Oscar Guanabarino, Luiz Heitor Correa de Azevedo, Andrade Muricy. Interessante notar que, num momento de transição e redefinição do "popular" pela emergência de uma consciência autoral, os recortes de noticiários contemplam a questão do plágio (candente à época e central para Mário, como mostra a fatura de Macunaima) e dos direitos de autor ${ }^{1}$. Já os recortes de teoria musical referem-se, sobretudo, a assuntos como prática e técnica pianística, nova notação musical e terapêutica musical.

Os álbuns "R. 34" e "R. 35" (que compreendem ori266 ginalmente o álbum Recortes III) reúnem a produção de crítica musical do próprio Mário de Andrade, inclusive do "jovem" Mário, isto é, os textos publicados de 1915 até a metade da década de 1920 (dificilmente rastreáveis de outro modo, devido ao seu caráter disperso). O primeiro ("R. 34") traz artigos publicados em jornais nacionais posteriormente incorporados por Oneyda Alvarenga à segunda edição de Música, doce música, publicada em 1964.

\footnotetext{
1 Vale lembrar, a propósito, de uma declaração de Mário a Oneyda Alvarenga: "E agora vem o mais importante e perigoso desta carta. Não sou de forma alguma contra o plágio em trabalhos de qualquer natureza, e muito tenho plagiado. Já roubei ideias artísticas, processos literários e pensamentos críticos. Talvez também esteja agora exagerando um bocado, mas a verdade geral é que não sou contra o plágio. O plágio tem qualidades ótimas: enriquece a gente, desentorpece uma exposição intelectual do excesso de citações, permite a gente milhorar ideias alheias boas, mas mal expressas incidentalmente etc. etc. Porém o plágio tem de ser consciente, porque só a consciência do roubo permite atingir a milhoria da coisa roubada e facilita o disfarce inteligente artístico do roubo. Aliás estou falando as palavras feias 'roubo' e 'roubar', quando se trata apenas de uma apropriação de coisa publicada, isto é, tornada pública, de todos nós” (Andrade e Alvarenga, 1983, p. 171; grifos no original).
} 
O segundo ("R. 35”) cobre o período de 1918-35 e reúne grande parte das críticas que publicou n'A Gazeta e no Jornal do Commercio (1918-1919), no Diário Nacional (19271932) e no Diário de S. Paulo (1933-1935), entre outros jornais e revistas, nem sempre identificados. Por sua vez, o álbum "R. 36" contém críticas e resenhas sobre a obra musical de Mário de Andrade, escritas (e frequentemente enviadas ao próprio Mário) por, entre outros, Andrade Muricy, João Caldeira Filho, Fernando Mendes de Almeida, Ernani Braga, Afonso Arinos de Melo Franco, Yan de Almeida Prado. Além desses, os álbuns numerados de "R. 39" até "R. 48" trazem recortes de críticas musicais publicadas em revistas especializadas, principalmente estrangeiras, destacando-se, pela preponderância entre elas, L'Arte Pianistica, Le Menestrel, La Musique, Die Musik, Le Monde Musical, periódicos que figuravam então entre os mais importantes do segmento especializado internacional.

A estratégia de aproximação ao cotidiano do autor através das críticas de circunstância se mostra pertinente, tendo em vista também que o próprio Mário se definiu mais de uma vez como homem de imprensa, e aquilatava a função educativa e a mediação social que o jornal - espécie de limiar sacrificial para ele -, por ser um veículo de maior penetração, poderia exercer na formação de um público leitor. Assim, parte significativa de sua militância modernista e atuação crítica se fez pela imprensa, com escritos de circunstância, não raro polêmicos, que davam vazão a um temperamento combativo que prefere refletir debatendo e se interrogando, como nos lembra Gilda de Mello e Souza (2009, p. 45). Além do mais, o jornal provava-se um meio mais adequado ao seu conceito - também dinâmico - de crítica como julgamento de valor transitório em face dos problemas em curso. Nos artigos de jornal se deixariam ver com mais clareza, como sugere Mello e Souza (2009), a personalidade eminentemente dialógica de Mário de Andrade, 
de que a série "O banquete", publicada na seção "O mundo musical" da Folha da Manhã, é exemplar, ou mesmo seu "temperamento socrático": aprecia ensinar e, quando leciona, preza o diálogo com os alunos ou consigo mesmo, recapitulando as incertezas, reformulando os conceitos, enfrentando os riscos inevitáveis da afirmação e da dúvida. Afinal, como diz Mário justamente para sua aluna Oneyda Alvarenga, importava-lhe a "felicidade de vida em que desprovido das vaidades entorpecedoras do ser, não tenho mais a convicção de que as minhas verdades sejam eternas, e muito menos as únicas verdades" (Andrade e Alvarenga, 1983, p. 25; grifo no original). Ora, como se sabe, o método maiêutico de Sócrates (cujo sentido originário é "através de um caminho") consiste não na transmissão de um saber pronto e acabado, mas na ideia de que o outro, o interlocutor, através da dialética, possa dar à luz suas próprias ideias, daí seus diálogos ficarem conhecidos como aporéticos ou inconclu268 sivos (Marcondes, 2004).

Em O banquete (Andrade, 1989), Mário procura, refletindo em registro satírico e em forma de diálogo, alinhavar as diretrizes e principais temas do seu pensamento estético, que estabelece justamente o inacabado como conceito básico. Lembramos, a propósito, que a Bucólica sobre a música brasileira - que se transformaria na parte teórica do Ensaio sobre a música brasileira (de 1928) - foi planejada por Mário como uma "artinha" na forma de diálogos entre professor e aluno, chamados por ele, respectivamente e a princípio, de Lusitano e Sebastião, conforme conta a Manuel Bandeira em carta de setembro de 1926. Esse pendor para o diálogo evidencia, como nota Mello e Souza (2009, p. 47; grifos no original),

[...] uma concepção aberta, totalmente dinâmica do ofício de pensar; uma crença profunda no exercício da inteligência, mas não na validade de suas conquistas; uma confiança, enfim, no pensamento como percurso e não como ponto de chegada. 
Talvez não fortuitamente seja um verbo, cunhado pelo próprio modernista e tão caro a ele, que parece encerrar esse sentido de abertura e inacabamento de um pensamento que se move ambiguamente entre a contingência e a permanência: "pensamentear".

Nessa mesma direção, o autor valoriza, em uma série de artigos sobre a vida de Chico Antonio, o que qualifica como a poesia surrealista deste cantador nordestino de cocos (que não permite enquadramento em assunto definido), o balanceio interno do andamento e o processo inventivo de improvisação pela forma variação, que frequentemente ocorre em diálogos e duelos cantados, conhecidos como "desafios" (Andrade, 1993a). Do diálogo d'O banquete emerge a ideia de que a música, dentre as várias artes e técnicas artísticas, é aquela que melhor traduz a estética do inacabado, pois é anti-intelectual e de sentido impreciso, eminentemente associativa, e exige, para se completar, a participação ativa e constante do público. Portanto, como sugere mais uma vez Mello e Souza (2009, p. 54), o discurso dialógico de Mário pode ser entendido, por sua vez, como um discurso inacabado, uma vez que

[...] se abre continuamente para o interlocutor, exigindo a cada passo a sua participação efetiva no debate. Enfim, é um discurso em que o próprio sujeito se coloca dividido, dilacerado, como que defrontando o seu duplo, na busca dramática de uma resposta.

Em sentido similar, Jorge Coli (1998, pp. 11 e 17) também chama a atenção para o pensamento "movente, plástico, avesso às belas estruturas teóricas cristalizadas" e "sem hierarquia", embora tenda a atribui-lo a certa "estreiteza de uma incapacidade teórica”, intentada, mas malograda. Já Carlos Sandroni (1988, p. 13) evoca a ideia de um pensamento "caprichoso, em lascas", que tende a atenuar a rigidez 
das fronteiras entre poesia e ensaio, mesclando imagens e abstrações. Hoelz (2015), por sua vez, aponta, a partir de dimensões da música inscritas no cotidiano de Mário de Andrade, os significados heurísticos mais amplos de sua perspectiva aberta e não afirmativa, entre e desde as fronteiras - que recusa ao mesmo tempo a dualidade e a síntese, enfatizando a contingência, a relação e o diálogo.

Isso posto, parece especialmente interessante, além de adequado, que a metodologia que se convencionou chamar de crítica genética venha sendo sistemática e consistentemente empregada para estudar as "matrizes de criação" no acervo e pensamento de Mário de Andrade (Lopez, 2002; Figueiredo, 2009). A crítica genética busca desnaturalizar o processo de criação, ao questionar a concepção de "obra" como uma unidade fechada ou mesmo "ontologizada", apreendendo-a dentro de um movimento mais amplo, no qual todas as etapas, desde as primeiras notas do escritor 270 até o livro já editado, são qualitativamente importantes, pois cada uma delas pode revelar uma camada mais ampla de sentidos, inclusive insuspeitados, que levam a reconstituir nexos intertextuais e a tensionar o sentido que certas versões interpretativas do autor ou da obra tendem a estabilizar (Bittencourt, 2011). Em linhas gerais, o que essa abordagem propõe é conferir uma nova dignidade aos documentos primários - tais como esboços, anotações de marginalia e outras peças menos "canônicas", como os escritos de circunstância -, que passam a ser considerados como "documentos de processo" em vez de meros rascunhos ou peças arqueológicas (Pino, 2007; Salles, 2009).

Como alerta Bittencourt, ao criticar a noção de "obra acabada" e reivindicar a importância do estudo das origens e dos caminhos do pensamento, por vezes arriscamos a incorrer em uma supervalorização desses materiais de "segunda ordem" - porque encarados apenas como imperfeições de uma obra final superior -, 
[...] como se eles contivessem um grau mais elevado de "pureza", ou fossem capazes de revelar alguma "verdade" imanente da obra em questão, por serem, em tese, menos mediados - uma espécie de "fiat" que atravessaria o cérebro ou os sentidos diretamente para a pena do escritor (Bittencourt, 2011, p. 20).

Assim procedendo, abriríamos mão dos ganhos oferecidos pela ideia de processo, qual seja, tomar o movimento como um todo, atentando para as várias dimensões que conferem sentidos normalmente diferenciados, quando não opostos. No entanto, também aqui é recomendável desenvolver uma escuta polifônica e levar a sério esses materiais jornalísticos que o próprio Mário de Andrade (1976, p. 11) admite ter escrito "sobre o joelho no intervalo das horas, destinando-os a existência dum só dia”. Talvez eles possam contribuir não apenas para questionar a noção de obra "canônica", como também para escapar de algumas das próprias interpretações, também elas canônicas, de que a obra de Mário de Andrade vem sendo objeto. Afinal, é preciso começar por reconhecer que nem o "ensaísmo", nem as "interpretações do Brasil" esboçadas nesses textos constituem realidades ontológicas estáveis, sendo antes objetos de disputas cognitivas e políticas e, nesse sentido, recursos abertos e contingentes, ainda que não aleatórios, no presente (Botelho, 2010).

\section{Mário de Andrade e a imprensa musical}

A trajetória de Mário de Andrade e sua relação com a imprensa está atravessada de ponta a ponta pela crítica de circunstância na área da música (Wisnik, 1979; Toni, 1990). Sua própria estreia na imprensa, em 1915, se dá com o artigo "No Conservatório Dramático e Musical: sociedade de concertos clássicos", publicado no Jornal do Commercio, a 11 de setembro, assinado M. Destacam-se, pelo volume e sistematicidade, sua colaboração no então recém-fundado Diário Nacional 
(de agosto de 1927 a setembro de 1932), órgão do Partido Democrático ao qual se filiaria; no Diário de S. Paulo (de 1933 a 1935), assinando a coluna "Música" em dias de concerto e preparando, periodicamente, textos mais elaborados para uma coluna especial da página 6, seção "Editoriais" - produção recolhida por Paulo Castagna em Música e jornalismo (Andrade, 1993b); e, finalmente, na Folha da Manhã, em que assume a redação do rodapé semanal "O mundo musical" reunido por Jorge Coli (1998) em Música final.

Argumentamos que essa crítica nos jornais é elemento central do sacrifício de Mario e ganha inteligibilidade como um tipo de força social reflexiva, que operava na conformação, normatização e rotinização de uma cultura musical "abrasileirada" - isto é, ao mesmo tempo moderna e nacional - dentro do circuito formado por compositores, intérpretes, repertório, público ouvinte e instituições de financiamento (Hoelz, 2015). Não se pode perder de vista que Mário de Andrade exerceu 272 o papel de crítico num meio cultural em que a vida musical desenvolvia-se tardiamente em relação à então capital do país, Rio de Janeiro, e aos centros europeus, sendo a própria crítica musical ainda incipiente e pouco especializada - desempenhada por homens de letras, músicos amadores e diletantes (Araújo, 1991). A visão integrada e processual da crítica adotada pelo modernista atentava, portanto, para a necessidade de formação dos portadores sociais capazes de realizar essa cultura musical, dadas as precárias condições socioculturais e técnicas de produção da música nesse "polo norte artístico", como o caracterizou certa feita, agravadas ainda pela epidemia do mal romântico. Como sugere Naves (2013), devemos levar em conta que interessavam ao Mário crítico, mais do que os aspectos relativos ao desempenho musical, os elementos culturais, sociais e éticos envolvidos nesse tipo de criação e performance.

A crítica feita por Mário de Andrade na imprensa assume sentido fundamentalmente democrático na medida em que busca colocar em diálogo recíproco e desestabilizador 
termos diferentes e desiguais entre si, que o processo social foi repondo como oposições estanques, como a relação entre erudito e popular. A crítica combinava, assim, uma abertura à incorporação de novas sonoridades e de vozes dissonantes de atores sociais excluídos, isto é, o reconhecimento das diferenças com uma percepção aguda das desigualdades sociais históricas. Nessa direção, Mário reivindica uma democratização do acesso aos concertos de modo geral e o acesso franco de toda a população especialmente em datas comemorativas, como expressa no artigo "Músicas do Dia de São Paulo", publicado no Diário Nacional de 27 de janeiro de 1931 (Andrade, 1931). O exercício da relativização cultural e histórica é um dos recursos mais mobilizados pelo autor para desconstruir preconceitos arraigados, como no caso da rígida etiqueta que determina o controle absoluto sobre os corpos nas salas de espetáculo. Em crítica de uma récita do Rigoletto no Teatro Municipal de São Paulo, Mário alude ao estado de sonolência que se apoderara de seu corpo devido a um dia fatigante de trabalho e ao espetáculo da noite anterior, terminado já na madrugada, para criticar a "imobilidade forçada e preconcebida a que a educação obriga atualmente os ouvintes" e a escureza das salas de espetáculo - que fizera com que, dias antes no primeiro ato de uma récita da Valquíria, Hunding, Sieglind e Siegmund mais parecessem "materializações espiritísticas que pessoas de carne e osso" (Recortes III, periódico não identificado, 14 de agosto de 1926). Contudo, para Mário, tudo isso não passaria de preconceito assentado por uma herança romântica.

O costume de acreditar a música uma arte profundíssima, uma arte capaz de dizer as coisas mais elevadas e sutis do pensamento e não uma arte dinâmica por essência, é que levou toda a gente a considerá-la com uma religiosidade ridícula e pedante. E então Wagner favorecido pelos 
histerismos dum rei ergueu a Meca musical de Bayreuth aonde maometanos de todas as raças foram adorar, numa escureza mística e num silêncio até onde os aplausos eram proibidos à Deusa falsa e "up-to-date" (Recortes III, periódico não identificado, 14 de agosto de 1926).

Assim, ouvindo o Rigoletto, o crítico diz ter invejado o público alegre dos teatros de Bolonha, Milão e Nápoles durante o século em que se criaram as formas clássicas da música. Público que sabia ouvir entre riso e fala, interrompendo a bulha só nos momentos altos das obras representadas, o que revelaria compreensão desinteressada da música, arte dinâmica que produz comoções sem determinação intelectual, "movendo músculos, agitando o sangue, criando saúde na gente" (Recortes III).

Em uma conferência manuscrita, o crítico paulista chama a atenção para outro aspecto desse problema resumido 274 na afirmação de que os concertos frequentemente se realizam perante uma "plateia de surdos". Caberia ao crítico, então, desenvolver um tipo de escuta aberta e se fazer ouvinte: “ouvir é manifestação do 'Amemo-nos uns aos outros'; e é por isso que as mais das vezes uma mãezinha ignorantíssima, ou a criada do artista, escutam melhor que plateia chique" (Conferência literária, s.d.). Tal disposição para ouvir implicaria, segundo Mário, uma "contemplação ativa" sempre vigilante em relação a dois tipos corriqueiros de equívocos: confundir cultura com tábuas da Lei - "o sujeito adquire um poder de regrinhas métricas, tudo o que não couber dentro delas não presta" - e procurar reconhecer, em vez de descobrir e compreender, o sentido que o artista encarnou na obra, ou seja, procurar nela "o que ele quer receber e não o que ela quer dar". Talvez por isso é que Mário de Andrade (1930a) tenha se autodeclarado o crítico mais "perdoador" de São Paulo: "Quando vou a concertos não é pra buscar defeitos dos recitalistas nem gozar com aqueles. Quero gozar 
é com os recitalistas. Aplaudi-los, escutar música boa, seja antiga ou moderna. Ser feliz enfim".

Portanto, a concepção de crítica de Mário não apenas admitiria como valorizaria o "direito de errar", tanto de intérpretes como de compositores. Por exemplo, comentando um recital do pianista Alonso Anibal da Fonseca, no Diário Nacional de 23 de outubro de 1929, aponta nas interpretações dele, "corretíssimas" e presas ao (e do) academismo, uma "abolição do perigo de errar" que o apartaria da "única coisa que é mais importante do que a perfeição terrestre: a aventura" (Andrade, 1929). O erro é, assim, associado pelo autor ao caráter de jogo da aventura, e importa mais que a perfeição, na medida em que envolve permanente risco e indeterminação, em suma, porque encerra a contingência. Na mesma perspectiva, o erro oferece liberdade fundamental para a imaginação e a criação artística, assim como constitui condição para o aprendizado; como diz a respeito de Francisco Mignone, no Diário Nacional de 21 de maio de 1930, "só tendo consciência de que pode errar, ele se sentirá livre, de posse daquela verdadeira liberdade que é mandar o mundo às favas, pra realizar o que a personalidade exige dele" (Andrade, 1930b). Para Mário de Andrade, Beethoven seria o antípoda desse artista mecânico, incapaz de transviar e viver a contradição, tipo de artista que ele aproxima dos heróis antigos de romance, "que quando eram bons eram só bons, e quando maus só maus". Beethoven, muito pelo contrário, é "terrivelmente humano [...] terrivelmente nós mesmos" (Andrade, 1993b, p. 208). Ademais, vale lembrar que o erro, justamente em virtude do que foi dito, poderia assumir para Mário sentido contestatório dos modelos e convenções europeus de saber, ensino e aprendizado, que determinavam a percepção e o tratamento do que era "erro". A ressignificação do erro aí ensejada permitiria diluir criticamente as fronteiras entre erudito e popular em favor do diálogo criativo. Não à toa, o trabalho "sacrificial" de tornar o Brasil brasileiro 
ganha expressão emblemática na adoção programática da língua portuguesa falada no Brasil e sua transposição para a escrita que aparece nos poemas, romances, ensaios, mas também nos textos de Mário de Andrade veiculados na imprensa. Nessa aproximação, o modernista se opunha e esvaziava a distinção entre norma culta e a língua portuguesa falada, adaptada e recriada na prática do cotidiano brasileiro. Nesse sentido, como sustenta Silviano Santiago (2008, p. 29), o erro poderia consistir em

[...] respostas culturais das classes populares - na sua formação étnica variada - ao centramento do ensino europeu e, como tal, deixa de ser erro para se apresentar como desvio e transgressão ao modelo imposto, reveladores que passam a ser, pelo avesso, de uma nacionalidade oficial envergonhada e recalcada, falsa e falsificante.

276 Em registro semelhante se dá a reflexão inusitada de Mário de Andrade sobre a malária, ou melhor, sobre a relação cultural dos homens amazônicos com a doença, que chama de "filosofia da maleita". Tal reflexão - que ganharia corpo no relato de viagem à Amazônia, publicado somente em 1976 - aparece já em duas crônicas publicadas no Diário Nacional em 1931, intituladas "Maleita I e II" (Lopez, 1976). Elas são como que fragmentos ou vislumbres da "utopia amazônica” de Mário de Andrade (Lopez, 2005), na qual os estigmas que há muito marcavam negativamente a civilização tropical sintetizada na Amazônia são como que transfigurados positivamente, como vem mostrando Botelho $(2012,2013)$. Operação modernista ligada à descoberta familiar, sem exotismos, do "primitivo", e ao projeto coletivo modernista de desrecalque cultural brasileiro. E que, por certo, também se prende à visão de mundo mais ampla de Mário de Andrade e sua percepção em relação às transformações radicais por que a sua própria sociedade, a paulista, 
passava. Com o avanço do capitalismo industrial, a rápida substituição de padrões de temporalidade, de sociabilidade, de práticas sociais e de valores angustiava um bocado Mário, que se fez crítico desse processo (Berriel, 1987). No caso da malária, Mário de Andrade imaginava serem certos estados fisiológicos e psíquicos, na prostração posterior aos acessos da doença, capazes de suspender a curiosidade, que ele associa negativamente ao progresso como princípio básico da civilização industrial, e de produzir relativa indiferença, valorizada por Mário como meio de contemplação e espírito reflexivo (Lima e Botelho, 2013). A "filosofia da maleita" se contrapõe, por exemplo, ao que se pode ler nos relatos de Carlos Chagas, nos quais a malária é considerada "o" mal da região, parecendo inaceitável, sobretudo, o modo como a doença ia se incorporando à vida da população. O que, naturalmente, do ponto de vista médico-científico com que se olha para o problema, era mesmo inaceitável, já que a moléstia seria evitável por medidas profiláticas. Assim, antes de aparentar uma simples oposição à civilização, a valorização do que poderíamos chamar genericamente de "cultura popular" (brasileiramente transfigurada a partir da valorização vanguardista do primitivo), por parte de Mário de Andrade, busca subsidiar uma visão mais plural de civilização, na qual haveria lugar para as diferenças e para uma convivência mais democrática entre elas, incluído seus embates.

Por fim, argumentamos que a potência contestatória que podemos identificar na análise que Mário de Andrade faz dos processos da música popular brasileira, tais como o improviso e a variação, encontra correspondência, em sua crítica musical, na valorização do que chama de espontaneidade da interpretação (Hoelz, 2015). Para dar um exemplo, essa espontaneidade é ressaltada na maneira de cantar da soprano ligeiro portuguesa Raquel Bastos, pois, "se às vezes discrepa um tanto da maneira tradicional com que 
certos autores são interpretados, traz em compensação um elemento novo, uma graça ignorada e uma perpétua surpresa" (Andrade, 1993b, p. 104). Essa capacidade de introduzir o novo, de gerar surpresa permanente é fundamental para Mário, porque, por um lado, transforma a interpretação num ato também de criação e, por outro, mantém a música unida à vida, sem o que ela se torna "uma coisa gelada, de cálculo, uma música dos músicos" (Andrade, 1993b, p. 104). Assim, a espontaneidade de interpretação permite romper com o que ele chama de "fetichismo" do "estilo" acalentado por uma pletora de músicos intérpretes à época, no qual os autores eram "encerrados, deformados e mumificados numa tradição falsa", que fixava uma maneira estereotipada e essencializada de interpretação da obra. A virtuosidade, percebida como "elemento independente da arte propriamente, valendo por si mesma, e consistindo na possessão malabarística", assim como a racionalidade 278 instrumental no Ocidente, "sorrateiramente se transformou numa invisível finalidade” (Andrade, 1993b, p. 201). Portanto, para Mário, a interpretação de uma peça musical jamais poderá assumir um sentido unívoco sem violentar sua liberdade e fazer tábula rasa da multiplicidade de sentidos que ela pode abrigar. E, por isso mesmo, a crítica, a fim de ajuizar essas interpretações, deve permanecer, em sua visão, como uma atividade aberta, eminentemente exploratória e inconclusa, bem como avessa ao que chamava de "valor-eternismo": a conversão das obras num absoluto, cujo sentido essencial e transcendente se projetaria fora do tempo. O que se denomina "estilo" e escola, portanto, se faz de contrastes, diferenças e conflitos, de desenvolvimentos que comportam direções e ramais e até mesmo involuções. E a crítica, nesse passo, permeada de um senso das contingências, deve acolher a dúvida e a surpresa, e, através do diálogo e do contraponto, como a música, ser capaz de ritmar a repetição e a diferença, o mesmo e o diverso, o contínuo e 
o descontínuo, revelando, enfim, o humano, ondulante e dinâmico, dilacerado e inacabado, sob os caprichos da forma, transfigurado em silêncios e sons.

Na obra e trajetória de Mario de Andrade, o sacrifício constitui a mediação que permite operar a passagem do individual para o social, do universal para o local, experimentados dramaticamente como dualidades que talvez devam, mas não podem, ser resolvidas (Fragelli, 2012). Daí o dilaceramento entre valor estético e função social da arte que perpassa o modernista paulista e que acaba por implicar o caráter paradoxal de seu sacrifício, o que, por sua vez, desloca o tema do cumprimento do destino intelectual, como o próprio autor reconhece ao passar em revista o movimento modernista em 1942: "Eis que chego a esse paradoxo irrespirável: tendo deformado toda a minha obra por um anti-individualismo dirigido e voluntarioso, toda a minha obra não é mais que um hiperindividualismo implacável!" (Andrade, 1978, p. 252). Assim, o sacrifício de sua subjetividade e de sua arte pelo funcional produz também o sacrifício do próprio social. Essa crítica já lhe fora feita pelo amigo Manuel Bandeira, em carta de 6 de agosto de 1931:

[...] a sua nobre tentativa de linguagem brasileira, feita no pensamento de nos unir mais os brasileiros, ideia portanto altamente socializante, se tem afirmado dessocializante: a maioria das pessoas simples que leem você sentem dificuldade de compreendê-lo. Quando você escreve "sube" e "intaliano", ninguém sente o seu desejo de comunhão nem o seu sacrifício, mas a sua personalidade indiscreta e tirânica querendo impor na linguagem literária escrita formas da linguagem popular ou culta falada que agradam à sua sensibilidade de grande escritor (Andrade, 2000, p. 516). 
Central na automodelagem de sua subjetividade, a ideia de sacrifício em Mário de Andrade, provavelmente nutrida a partir de seu catolicismo todo particular, parece, assim, responder também objetivamente às dificuldades suscitadas nas contradições históricas da sociedade brasileira em seu processo de formação autocrático reposto pela modernização conservadora. Mas o sacrífico não apenas figura como tema na vida e obra de Mário de Andrade, configura propriamente uma "forma" que, como tal, articula essas dimensões e sua expressão, conferindo-lhes significado e tornando-lhes comunicável em termos de relações sociais compartilhadas -, para lembrarmos uma discussão clássica sobre o social, não como um contexto externo, mas como elemento que penetra a forma e se torna parte do processo de composição (Lukács, 2015). Por isso, a forma sacrificial merece ser levada a sério e mesmo radicalizada para que se possa chegar o mais próximo possível da posição de Mário 280 de Andrade e do sentido sociológico ricamente ambíguo que encerra na reflexão do cumprimento de seu destino intelectual e no debate sobre cultura e política no Brasil moderno de que faz parte.

A despeito da opinião de Manuel Bandeira, expressa anteriormente, e de sua pertinência ou não, a aproximação da língua escrita da língua falada, defendida por Mário de Andrade, não implicava mera transposição de um registro oral - popular ou culto - ao escrito, mas, antes, o trabalho estético de recriação da linguagem literária a partir dessa aproximação cheia de riscos. Assim, se Mário aproxima imprensa e literatura para tornar esta mais familiar do público e não para estetizar a imprensa, como argumentamos, através da crítica musical, o caso aqui estudado, Mário procurou abrasileirar a cultura musical europeizada que então grassava e, sobretudo, criar passagens entre erudito e popular (ainda que isso também não se realizasse sem ambiguidades). Ao colocar erudito e popular em relação recíproca, 
estabelecendo um diálogo criativo entre eles, buscava também ampliar o acesso cultural do público à música de concerto. Assim, o trabalho efêmero do crítico na imprensa, essa espécie de limiar, projetaria uma "obra" de sentido permanente para as gerações de músicos que se seguiram, dramatizando ritualisticamente o ato sacrifical de Mário de Andrade. Afinal, como indicam Mauss e Hubert (2005), as forças sociais ambíguas, investidas e acumuladas no objeto do rito, são, na consumação do sacrifício, liberadas e redistribuídas na sociedade.

\section{André Botelho}

é professor adjunto da Universidade Federal do Rio de Janeiro (UFRJ), pesquisador do CNPq e da Faperj (Cientista do Nosso Estado).

\section{Maurício Hoelz}

é pós-doutorando em Sociologia na UFRJ; bolsista da Faperj.

\section{Bibliografia}

ANDRADE, M. 1929. "Alonso Anibal da Fonseca”. Diário Nacional, 23 out., p. 7. . 1930a. "Frank Smit". Diário Nacional, 28 ago., p. 6. . 1930b. "Músicas novas". Diário Nacional, 21 maio, p. 7. .1931. "Músicas do Dia de São Paulo". Diário Nacional, 27 jan., p. 4. 1968. Mário de Andrade escreve cartas a Alceu, Meyer e outros.

Organização de Lygia Fernandes. Rio de Janeiro: Editora do Autor. 1976. Música, doce música. São Paulo/Brasília: Martins/MEC. . 1978. Aspectos da literatura brasileira. São Paulo: Martins. 1989. O banquete. São Paulo: Duas Cidades. . 1993a. Vida do cantador. Belo Horizonte/Rio de Janeiro: Villa Rica. . 1993b. Música e jornalismo: Diário de S. Paulo. Organização de Paulo

Castagna. São Paulo: Edusp/Hucitec. 2000. Correspondência Mário de Andrade Ẽ Manuel Bandeira. São

Paulo: Edusp/IEB. . 2010. Correspondência Mário de Andrade Ẽ Henriqueta Lisboa. São

Paulo: Edusp/IEB. 
2015. A lição do amigo. Cartas de Mário de Andrade a Carlos

Drummond de Andrade. São Paulo: Companhia das Letras. s.d. "Losango cáqui". In: . De Pauliceia desvairada a Café (poesias completas). São Paulo: Círculo do Livro.

ANDRADE, M.; ALVARENGA, O. 1983. Cartas. São Paulo: Duas Cidades.

ARAÚJO, R. B. 2014. "Um grão de sal: autenticidade, felicidade e relações de amizade na correspondência de Mário de Andrade com Carlos Drummond". História da Historiografia, Ouro Preto, n. 16, pp. 174-85. ARAÚJO, V. G. 1991. A crítica musical na imprensa paulista: 1854-1875. Dissertação de mestrado. São Paulo: PUC.

BASTOS, E. R.; BOTELHO, A. 2010. "Para uma sociologia dos intelectuais". Dados - Revista de Ciências Sociais, v. 53, n. 4, pp. 889-919.

BENDIX, R. 1986. Max Weber, um perfil intelectual. Brasília: Ed. UnB.

BERRIEL, C. E. O. 1987. Dimensões de Macunaíma: filosofia, gênero e época. Dissertação de mestrado. Campinas, SP: IEL-Unicamp.

BITTENCOURT, A. V. 2011. O Brasil e suas diferenças: uma leitura genética de populações meridionais do Brasil. Dissertação de mestrado. Rio de Janeiro: IFCS-UFRJ.

BOMENY, H. 2012. Um poeta na política: Mário de Andrade, paixão e compromisso. Rio de Janeiro: Casa da Palavra.

BOTELHO, A. 2010. "Passado e futuro das interpretações do país". Tempo Social, USP, n. 22, pp. 47-66.

2012. De olho em Mário de Andrade: uma descoberta intelectual e sentimental do Brasil. São Paulo: Claroenigma.

. 2013. "A viagem de Mário de Andrade à Amazônia: entre raízes e rotas”. Revista do Instituto de Estudos Brasileiros, n. 57, pp. 15-50.

2015. Posfácio. In: ANDRADE, M. A lição do amigo. Cartas de Mário de Andrade a Carlos Drummond de Andrade. São Paulo: Companhia das Letras.

CAVALCANTI, M. L. 2004. "Cultura popular e sensibilidade romântica: as danças dramáticas de Mário de Andrade”. RBCS - Revista Brasileira de Ciências Sociais, v. 19, n. 54, pp. 57-78.

COLI, J. (org.). 1998. Música final. Campinas, SP: Ed. Unicamp.

CONFERÊNCIA literária [manuscrito de Mário de Andrade]. s.d. Série Manuscritos IEB-USP.

FIGUEIREDO, T. M. L. S. N. 2009. Café: o trajeto da criação de um romance inacabado de Mário de Andrade. Tese de doutorado. São Paulo: FFLCH-USP.

FRAGELLI, P. C. 2012. A paixão segundo Mário de Andrade. Dissertação de mestrado. São Paulo: FFLCH-USP. 
2013. "Engajamento e sacrifício: o pensamento estético de Mário de Andrade”. Revista do Instituto de Estudos Brasileiros, n. 57, pp. 83-110.

HOELZ, M. 2015. Entre piano e ganzá: música e interpretação do Brasil em Mário de Andrade. Tese de doutorado. Rio de Janeiro: IFCS-UFRJ. JARDIM, E. 2015. Mário de Andrade: Eu sou trezentos. Vida e obra. Rio de Janeiro: Edições de Janeiro.

LIMA, N. T.; BOTELHO, A. 2013. "Malária como doença e perspectiva cultural nas viagens de Carlos Chagas e Mario de Andrade à Amazônia”. História, Ciências, Saúde-Manguinhos, n. 20, pp. 745-63.

LOPEZ, T. A. 1976. "Mário de Andrade no Diário Nacional". In: ANDRADE, M. Taxi e crônicas no Diário Nacional. São Paulo: Duas Cidades/Secretaria de Cultura, Ciência e Tecnologia. 2002. "La bibliothèque de Mário de Andrade: une moisson de création engrangée”. Genèses - Revue Internationale de Critique Génétique, Paris, n. 1, pp. 45-65. . 2005. "O Turista Aprendiz na Amazônia: a invenção no texto e na imagem”. Anais do Museu Paulista, v. 13, n. 2, pp. 135-64.

LUKÁCS, G. 2015. A alma e as formas. Belo Horizonte: Autêntica Editora. MARCONDES, D. 2004. Iniciação à história da filosofia: dos pré-socráticos a Wittgenstein. Rio de Janeiro: Zahar.

MAUSS, M.; HUBERT, H. 2005. Sobre o sacrificio. São Paulo: Cosac Naify.

MELO E SOUZA, G. 2009. Exercícios de leitura. São Paulo: Duas Cidades/ Ed. 34.

MICELI, S. 2001. Intelectuais à brasileira. São Paulo: Companhia das Letras. . 2009. "Mário de Andrade: a invenção do moderno intelectual brasileiro”. In: SCHWARCZ, L.; BOTELHO, A. (orgs.). Um enigma chamado Brasil. São Paulo: Companhia das Letras.

MONTEIRO, P. M. 2012. "Coisas sutis, ergo profundas: o diálogo entre Mário de Andrade e Sérgio Buarque de Holanda”. In: MONTEIRO, P. M. (org.). Mário de Andrade e Sérgio Buarque de Holanda: correspondência. São Paulo: Companhia das Letras/Instituto de Estudos Brasileiros/Edusp.

MORAES, M. A. 2007. Orgulho de jamais aconselhar: a epistolografia de Mário de Andrade. São Paulo: Edusp/Fapesp.

NAVES, S. C. 2013. O Brasil em unissono. Rio de Janeiro: Casa da Palavra. PINO, C. A. 2007. "Gênese da gênese". Revista Ciência e Cultura - SBPC, v. 59, n. 1, pp. 24-27.

SACHS, S. 1993. "Um crítico no jornal”. In: ANDRADE, M. Vida literária. São Paulo: Edusp/Hucitec. 
SALLES, C. A. 2009. Gesto inacabado: processo de criação artística. São Paulo: Annablume.

SANDRONI, C. 1988. Mário contra Macunaíma. São Paulo: Vértice.

SANTIAGO, S. (org., prefácio e notas). 2002. Carlos Ẽ Mário: correspondência completa de Carlos Drummond de Andrade e Mário de Andrade. Rio de Janeiro: Bem-Te-Vi. 2008. O cosmopolitismo do pobre. Belo Horizonte: Ed. UFMG.

TONI, F. C. 1990. O pensamento musical de Mário de Andrade. Tese de doutorado. São Paulo: ECA-USP.

WISNIK, J. M. 1979. Dança dramática (poesia/música brasileira). Tese de doutorado. São Paulo: FFLCH-USP. 


\section{O MUNDO É UM MOINHO: SACRIFÍCIO E COTIDIANO EM MÁRIO DE ANDRADE}

ANDRÉ BOTELHO

\section{MAURÍCIO HOELZ}

Resumo: A atuação prolífica e diversa de Mário de Andrade na imprensa constitui um dos vezos mais recursivos em que transcorre a sua vida-obra. Concentrando-nos na atuação do líder modernista como crítico musical na imprensa, argumentamos que é a ideia de "sacrifício" - indissociável da questão do cumprimento do destino intelectual - que permite articular as diferentes dimensões entre trajetória e obra em Mário de Andrade, tornando relativa a própria dualidade entre permanência e efemeridade de sua obra intelectual. Sustentamos ainda que, sociologicamente, essa ideia faz sentido justamente porque não há, no Brasil dos modernistas, algo estruturado em termos próximos aos de um campo intelectual autônomo, com posições diferenciadas e regidas exclusivamente por um habitus próprio em seu interior e nas relações inclusivas mantidas por seus membros com a sociedade.

Palavras-chave: Mário de Andrade; Sacrifício; Destino Intelectual; Imprensa; Crítica Musical; Modernismo Brasileiro.

\section{THE WORLD IS A MILL: SACRIFICE AND EVERYDAY LIFE IN MÁRIO DE ANDRADE}

Abstract: Mário de Andrade's prolific and diverse activity in the press is one of the most recursive features of his life and work. Focusing on the modernist leader's role as a music critic in the press, this article argues that the idea of "sacrifice", inseparable from the fulfilment of an intellectual destiny, is central to articulate the different dimensions of his trajectory and work. It also contends that the question of "sacrifice" is what puts the duality between permanence 
and transience of his work into perspective. Finally, this article emphasizes that the sociological relevance of this idea is tied to the absence, in the Brazilian modernist context, of an autonomous intellectual field in which the different actors' positions, as well as in its internal and external relationships, were exclusively regulated by a particular habitus.

Keywords: Mário de Andrade; Sacrifice; Intellectual Destiny; Press; Music Criticism; Brazilian Modernism.

Recebido: 24/11/2015 Aprovado: 04/12/2015 